\title{
Modulation Effects of Piracetam and Ginkgo Biloba on the Cognitive and Working Memory Functions: Psychometric Study
}

Hayder M Alkuraishy ${ }^{*}$, Ali I Algareeb, Ali K Albuhadilly and Basim M Almgoter

Department Of Pharmacology, Toxicology and Medicine College of Medicine Almustansiriya University, Iraq

*Corresponding author: Hayder M Alkuraishy, Department Of Pharmacology, Toxicology and Medicine College of Medicine Almustansiriya University, P.O. Box 14132 Iraq /Baghdad, Tel: +96407906230487; E-mail:Hayderm36@Yahoo.Com

Received date: Aug 26, 2014, Accepted date: Sep 22, 2014, Published date: Sep 28, 2014

Copyright: (C) 2014 Alkuraishy HM, et al. This is an open-access article distributed under the terms of the Creative Commons Attribution License, which permits unrestricted use, distribution, and reproduction in any medium, provided the original author and source are credited.

\begin{abstract}
Extracts of ginkgo biloba have been broadly prescribed toward advance symptoms of cognitive dysfunction ranging in severity from mild memory loss to dementia also; in delaying the development of dementia; ginkgo biloba has been encouraged commercially as a smart medicine to augment the brain function of healthy people. Piracetam is a no tropic remedy correlated to inhibitory $\gamma$-aminobutyric acid (GABA) neurotransmitter. Piracetam may be the initial agent acting on cognitive function without sedation. Thirty subjects (30 males) arbitrarily choose as of medical college students. The contributors were allowable to perform mutually on the psychomotor performance device tester and the computerized n-back test (working memory task) to obtain knowledge from those tests sooner than the commencing of the examination. All psychometric response time and working memory test parameters calculated previous to the experimental research, so the identical volunteers considered as control and through four days of receiving the ginkgo biloba $60 \mathrm{mg} /$ day (trunature GSL),piracetam $800 \mathrm{mg} /$ day (neutrophil) or both drugs so the enrolled participants divided into three groups. Group A take ginkgo biloba, group B take piracetam and group C take piracetam and ginkgo biloba.
\end{abstract}

Piracetam significantly improve cognitive and working memory at all levels $\mathrm{P}<0.05$ while it showed insignificant effects on psychometric reaction time parameters except it ameliorate the total reaction time (TRT) $P<0.05$. The differential effects of ginkgo biloba showed significant effects on psychometric reaction time and cognitive central Integrity $\mathrm{P}<0.05$ and insignificant effects on working memory accuracy except at level I-Back where it produced significant effects $\mathrm{P}<0.05$. Combined effects of ginko biloba and piracetam on psychomotor performances, cognitive function and working memory produced significant effects $\mathrm{P}<0.05$.

Conclusion: Combined effects of piracetam and ginkgo biloba produced more significant effects than either ginkgo biloba or piracetam alone on cognitive function and working memory.

Keywords: Ginkgo biloba; Piracetam; Cognitive function; Working memory; Psychomotor.

\section{Introduction}

Extracts of ginkgo biloba have been broadly prescribed toward advance symptoms of cognitive dysfunction ranging in severity from mild memory loss to dementia also; in delaying the development of dementia; ginkgo biloba has been encouraged commercially as a smart medicine to augment the brain function of healthy people. The active components of ginkgo biloba are flavonoid glycosides and terpene lactones[1]. Mechanisms accredited to ginkgo comprise free-radical scavenging, antioxidant, anti-inflammatory and modulation of central neurotransmitter [2-5]. Additionally; it inhibits nitric oxide production during ischemia[6,7], ginkgolides present in ginkgo biloba have been classified as nootropic agent also; the haemorheological property of ginkgo and the assumed effects on neurotransmitters are reasonable mechanisms by which the ginkgo might not merely apply a protective effect against dementia but also improve standard cognition in normal healthy subjects [8,9].

Piracetam is a nootropic remedy correlated to inhibitory $\gamma$ aminobutyric acid (GABA) neurotransmitter. Piracetam may be the initial agent acting on cognitive function without sedation. Despite of resemblance of piracetam with $\gamma$-aminobutyric acid and its aptitude toward adapt purpose of numerous brain neurotransmitter organizations, piracetam effects was believed to be independent on straight connections with any (GABA) postsynaptic receptors. Piracetam produced alterations in a number of brain neurotransmitters systems so leading to neuroprotective and anticonvulsant effects thus; influence the neuronal plasticity which per se improves glucose and oxygen metabolism in hypoxic brain area thus piracetam is effective in treatment of dementia and cognitive disorders $[10,11]$.

Frequent administration of piracetam and ginkgo biloba may result in so called behavioral sensitization, which plays an important role in cognition so; an increased reaction to the same dose of drug after preceding long-term alternating administration of this drug. Behavioral sensitization is frequently parented subsequent to equally repetitive doses and appliance of a confront dose directed following a positive era of extraction via alterations in neurotransmission connected with recurring coverage to these drugs $[12,13]$.

At a cognitive stage, executive functions possibly will be partially affected via of working memory a system that provisionally stores and manipulates information desirable for multifaceted cognition trail test such as understanding, preparation or interpretation [14]. 
Working memory is the cognitive system that permits us to remain energetic a partial quantity of knowledge for a short era of time (approximately, a few seconds) and was former named as "short term memory." It was after that consideration to have two functions storing objects that we have to recall in a few seconds, while cognitive scientists carry on to consider in the simple storage reason, their faith in the way by the reality of neurological patients who are impaired in petite (short) term memory task, although perform usually on extended (long) term memory task $[15,16]$.

Working memory plays a vital function in numerous high-level cognitive processes. The widespread vision grasps so as to active workings of working memory are largely deliberate and aware. This commencement is often articulated clearly, but it is best reflected in the scenery of major working memory tasks [17].

Consequently the aims in the attending study were to approximate the advancement outcomes of ginkgo and or piracetam on cognitive, psychomotor performances and working memory functions in normal young male's healthy persons and to confirming the modulation effects.

\section{Subjects and Methods}

The present experimental work was done in pharmacological laboratory research site in college of medicine/ Baghdad-Iraq from January to march 2014. A scientific committee amended and permitted the research and verbal approval taken from all the participants. Healthy volunteers (30 males) arbitrary chosen as medical college students. They were fit and free from any disease with age ranged 20-24 years. The volunteers were allowable to perform mutually on psychomotor tester and working memory test to obtained familiarity by way of those tests before commencing of the experimental trail.

Leeds psychomotor tester: It is a device used to compute human psychomotor vigilance performance and critical flicker versus fusion threshold.

The standard total (complex versus simple) reaction time (TRT) is the response to brilliant red color light source as emerged randomly and via urgent the key wherever the scarlet/red beams revealed. So; the duration of time wanted for red color recognition be described as (RRT) recognition reaction time which corresponded toward the instant starting stimulus beginning to the commencement of motor action, while the duration of time starting movement act to the end of response named (MRT) movement reaction time. Summing up of both time reaction times called total reaction time (TRT) [18].
(CFFT) Critical fusion -flicker threshold: It measures the cognitive central integrity, this designed by asking the volunteers to give concentration to the four illuminated red light seat and to react at what time the illuminated light changed. The mean of four ascending called fusion threshold while the mean of descending called flickering threshold, the best value for fusion $>30 \mathrm{~Hz}$ while best value for flickering $<30 \mathrm{~Hz}$ [19]

Computerized N-Back Task: explained by Yung-Nien; the eight squares at diverse positions were accessible sequentially on computer monitor at rate of three second. An answer was required each time the solitary stimuli synchronized the single accessible $\mathrm{N}$ position reverse in succession. Within I-BACK site the aim be any square location that is the same of preceding square location while in II-BACK the aim be square location same to the extra square location two trial reverse ,moreover ; the III-BACK test the square setting was similar to added square site three trail back. The computer monitor sequentially counting the accuracy rate which was the number of corrected responses after the volunteers completed the response via pressing letter A on computer keyboard [20].

All psychometric response time and working memory test parameters calculated previous to the experimental research ,so the identical volunteers considered as control and through four days of receiving the ginkgo biloba $60 \mathrm{mg} /$ day (trunature GSL) ,piracetam $800 \mathrm{mg} /$ day (nootropil) or both drugs so the enrolled participants divided into three groups.Group A take ginkgo biloba, group B take piracetam and group C take piracetam and ginkgo biloba. All the pharmaceutical preparations purchased from private pharmacy.

Statistical analysis was prepared by means of using paired t-test. All the data are accessible as (mean $\pm \mathrm{SD}$ ) when $\mathrm{p}$ value $<0.05$ considered significant effect.

The statistical explanation and analysis was done via expressing all data as mean $\pm \mathrm{SD}$ using T-test (paired) when the $\mathrm{p}$ value $<0.05$ considered as significant.

\section{Results}

Piractam significantly improve cognitive and working memory functions at all levels $\mathrm{P}<0.05$ while it showed insignificant effects on psychometric reaction time parameters except it ameliorate the total reaction time (TRT) $\mathrm{P}<0.05$ (Table 1).

\begin{tabular}{|c|c|c|c|c|c|c|c|c|}
\hline \multicolumn{4}{|c|}{ Psychometric Reaction time } & \multirow{3}{*}{$\begin{array}{l}\begin{array}{l}\text { Cognitive central } \\
\text { Integrity }\end{array} \\
\text { AFFF }\end{array}$} & \multicolumn{3}{|c|}{ Working memory accuracy (\%) } & \multirow{3}{*}{ III-Back } \\
\hline \multirow{2}{*}{ Variables } & TRT & RRT & MRT & & & & & \\
\hline & (ms) & (ms) & (ms) & & & & & \\
\hline Before & $525.71 \pm 73.5$ & $434.8 \pm 15.4$ & $90.9 \pm 58.1$ & $41.32 \pm 0.007$ & $40.44 \pm 0.151$ & $85.4 \pm 7.3$ & $\begin{array}{ll}83.6 & \pm \\
16.3 & \end{array}$ & $67.6 \pm 12.3$ \\
\hline P-Value & $<0.05$ & $>0.05$ & $>0.05$ & $<0.05$ & $<0.05$ & $<0.05$ & $<0.05$ & $<0.05$ \\
\hline
\end{tabular}


Citation: Alkuraishy H, Algareeb A, Albuhadilly A, Almgoter B (2014) Modulation Effects of Piracetam and Ginkgo Biloba on the Cognitive and

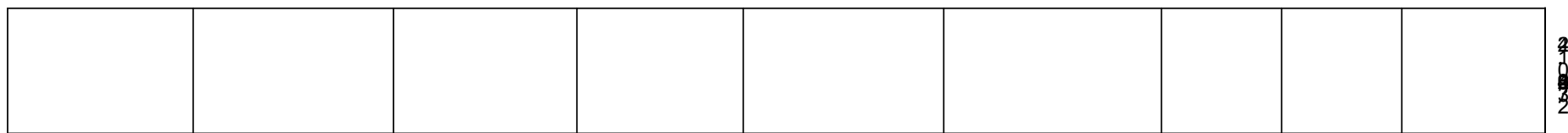

Table 1: Differential effects of piracetam on psychomotor performances, cognitive function and working memory. TRT=total reaction time, $\mathrm{RRT}=$ recognition reaction time, $\mathrm{MRT}=$ movement reaction time, $\mathrm{AFFF}=$ ascending flicker fusion frequency, $\mathrm{DFFF}=\mathrm{descending}$ flicker fusion frequency

Differential effects of ginkgo biloba showed significant effects on insignificant effects on working memory accuracy except at level ipsychometric reaction time and cognitive central integrity $\mathrm{p}<0.05$ and back where it produced significant effects $\mathrm{p}<0.05$ (Table 2 ).

\begin{tabular}{|c|c|c|c|c|c|c|c|c|}
\hline \multicolumn{4}{|c|}{ Psychometric Reaction time } & \multirow{3}{*}{$\begin{array}{l}\begin{array}{l}\text { Cognitive } \\
\text { Integrity }\end{array} \\
\text { AFFF }\end{array}$} & \multicolumn{3}{|c|}{ Working memory accuracy (\%) } & \multirow{3}{*}{ III-Back } \\
\hline \multirow{2}{*}{ Variables } & TRT & RRT & MRT & & \multirow{2}{*}{ DFFF } & \multirow{2}{*}{ I-Back } & \multirow{2}{*}{ II-Back } & \\
\hline & (ms) & (ms) & (ms) & & & & & \\
\hline Before & $633.71 \pm 73.5$ & $477.8 \pm 15.4$ & $155.91 \pm 58.1$ & $42.32 \pm 0.007$ & $42.41 \pm 0.151$ & $89.4 \pm 7.3$ & $81.6 \pm 16.3$ & $65.6 \pm 12.3$ \\
\hline P-Value & $<0.05$ & $<0.05$ & $<0.05$ & $<0.05$ & $<0.05$ & $<0.05$ & $>0.05$ & $>0.05$ \\
\hline
\end{tabular}

Table 2: Differential ginkgo biloba effects on psychomotor performances, cognitive function and working memory; TRT=total reaction time, $\mathrm{RRT}=$ recognition reaction time, $\mathrm{MRT}=$ movement reaction time, AFFF=ascending flicker fusion frequency, DFFF=descending flicker fusion frequency

Combined effects of ginkgo biloba and piracetam on psychomotor performances, cognitive function and working memory produced significant effects $\mathrm{p}<0.05$ (Table 3 ).

\begin{tabular}{|c|c|c|c|c|c|c|c|c|}
\hline \multicolumn{4}{|c|}{ Psychometric Reaction time } & \multirow{3}{*}{$\begin{array}{l}\text { Cognitive central Integrity } \\
\text { AFFF }\end{array}$} & \multicolumn{4}{|c|}{ Working memory accuracy(\%) } \\
\hline \multirow{2}{*}{ Variables } & TRT & RRT & MRT & & \multirow{2}{*}{ DFFF } & \multirow{2}{*}{ I-Back } & \multirow{2}{*}{ II-Back } & \multirow{2}{*}{ III-Back } \\
\hline & (ms) & (ms) & (ms) & & & & & \\
\hline Before & $525.71 \pm 72.5$ & $477.8 \pm 15.4$ & $47.91 \pm 57.1$ & $40.32 \pm 0.007$ & $41.43 \pm 0.151$ & $81.4 \pm 7.3$ & $82.6 \pm 16.3$ & $64.6 \pm 12.3$ \\
\hline $\mathrm{p}$-value & $<0.05$ & $<0.05$ & $<0.05$ & $<0.05$ & $<0.05$ & $<0.05$ & $<0.05$ & $<0.05$ \\
\hline
\end{tabular}

Table 3: Dual differential combined effects of piracetam and ginkgo biloba on psychomotor, cognitive and working memory performance functions.TRT=total reaction time, $\mathrm{RT}=$ recognition reaction time, MRT=movement reaction time, $\mathrm{AFFF}=$ ascending flicker fusion frequency, $\mathrm{DFFF}=$ descending flicker fusion frequency 


\section{Discussion}

The present study showed that piracetam and ginkgo biloba produced significant differential effects on psychomotor performances, cognitive function and working memory when used alone but combined effects of both piracetam and ginkgo biloba produced significant effects at all level of psychomotor performances, central cognitive integrity and working memory process.

Piracetam produced significant effects only on total reaction time of psychomotor performances while it produced insignificant effects on recognition and movement reaction time, also it ameliorate the cognition and working memory.

The main action of the piracetam is mainly unidentified but piracetam was frequently thought to adapt cholinergic receptors in the hippocampus to amplify the special effects of acetylcholine, which is well-known for advancing memory as it is profoundly implicated with the programming of novel memories [21].

Preceding revisions of experimental studies proposed that piracetam ultimately adjust neurotransmission and neuroplasticity [22]. Cholinergic system is accountable for memory and learning, particularly the basal forebrain connections to hippocampus and cortex, is identified to be mainly pretentious in Alzheimer's disease so acetylcholine role has been enhanced by piracetam through cholinergic muscarinic receptors, which be concerned in cognitive and memory progression effects of piracetam [23]. Additionally, piracetam might activate NMDA glutamate receptors, which were concerned with memory, learning progressions and increase permeability of cell membrane also; piracetam might apply its universal consequence on brain neurotransmission via modulation of $\mathrm{Na}+/ \mathrm{K}+$ ion channels and increasing in oxygen expenditure at cerebral cortex [24,25].

Nithiananda et al. and Levent et al. studies showed that utilized of piracetam is predictable to balance cholinergic indirectly by restraining the damaging of acetylcholine and directly by escalating the appearance of choline- acetyltransferase, also; piracetam improve oxidative stress parameters in adding to improvement of cholinergic activity, this might explain the capability of piracetam to recover and improvement in the behavioral performance [26,27] therefore; all these findings supports our results mainly on cognitive and memory functions.

Ginkgo biloba significantly improve the psychomotor performances and cognitive function so the experimental enhancements in cognitive capacity owed to the pragmatic augmention in blood supply which increases the delivery of glucose and oxygen to the cerebral neurons [28]. Enhancements in intentional purposes might reflect the capability of ginkgo biloba to inhibition of monoamine oxidase enzyme (MAO) so increase levels of monoamine like noradrenalin, dopamine and serotonin which in consequences enhance monoamine neurotransmitters [29]. In spite of the advantageous actions of ginkgo biloba in the present study but in other studies founded insignificant effects within five days of ginkgo biloba therapy in healthy volunteers, the insignificant effects might due to short period of ginkgo biloba therapy or very low dose [30]. While the exact role of cognitive enhancements showed in this experimental study are appreciable and ginkgo biloba appeared to produce significant improvement in the cognitive function at $60 \mathrm{mg} /$ day [31].

Active ingredients' of ginkgo biloba influence principally muscarinic and adrenergic receptors and it has been confirmed that ginkgo extracts increase the number of muscarinic and $\alpha-2$ adrenergic receptors, which induce uptake of choline in synapses [32].

The antioxidant possessions of ginkgo biloba are chiefly ascribed to flavonoid and trepenoid portions which are encloses antagonists of platelet-activating factor and diminish ischemia-induced neurotoxicity and slow down glutamate-induced excitotoxicity .In adding to universal neuroprotective possessions, numerous behavioral revises designate that ginkgo biloba renovated stressful induced elevation of cerebral catecholamine, serotonine and cortisol near the normal level. Also Ginkgo biloba reduced age related diminished 5-HT1A receptors desensitization [33-35].

In dissimilarity to benzodiazepines which are frequently used for improving anxiety ginkgo does not weaken vigilance and cognitive performance and revisions in normal healthy persons and in minded blighted subjects establish so as to ginkgo has psychomotor performance triggering property and long-term use of ginkgo not cause dependence [36].These support our results of psychomotor and cognitive enhancement via ginkgo biloba.

Flavonoid and ginkgolide of ginkgo biloba have free radical scavengering and antioxidant effects [37]. Furthermore, ginkgolide decrease neurotransmitter receptor loss provoked by aging [39], the present study demonstrates that ginkgo potentially augment the acquirement and recital of visual working memory as revealed by enhanced reaction exactness in a cognitive test. The present study also showed that the vigilance attractive properties of ginkgo biloba may be linked to the improvement in central cognitive integrity. Previous research on ginkgo biloba management by Jonas et al. showed that advanced in reasoning whilst therapy started days to months prior to beginning of preparation assemblies. The present experimental study nevertheless, proves that ginkgo treatment expose enhanced learning in young adult volunteers and achievement of working memory test was agreeable to the ginkgo biloba induced cognitive improvements ,so ; this study offers proof that ginkgo biloba be uniformly effectual in ameliorating the cognition and psychomotor performances [40]. Working memory performances, conversely, be mostly unaltered via ginkgo biloba therapy, but the present study results so sustain the idea so as to continuing ginkgo biloba therapy do produced only beneficial effects, at least in on I-back of working memory task [41]

Combined ginkgo biloba and piracetam effects showed profound synergistic effects on cognitive, working memory functions and psychomotor performances because piracetam modulates ginkgo biloba effect on working memory also ginkgo biloba potentiate effects of piracetam on psychomotor performance.

Shi-Jin and Zhan-You 2012 study showed the ginkgo biloba may manipulate arousal and attention via dopaminergic amplification leading to increased in the arousal and attention capability [42]. Additionally, conclusions from previous research done by Ixchel Herrera and Ignacio et al. on healthy subjects entail that the dopaminergic advancing agents like bupropion and sertraline possibly will improve vigilance and psychomotor performance in patients with depressive disorders , also duloxetine improve the cognitive functions in depressed patients more significantly than placebo and the consequence be chiefly determined through enhancement in working memory ,moreover; venlafaxine showed better response in cognitive function than trazodone in randomized study of patients with depressive disorders [43,44]. De Jongh et al. study founded enhancement in awareness but not memory in older depressed 
patients taken venlafaxine [45]. Entertainingly, duloxetine augment affecting dispensation in normal volunteers [46]. Therefore, selective serotonine-noradrenaline reuptake inhibitors (SNRIs) are valuable in psychomotor performances and cognitive functions.

So ginkgo biloba improve psychomotor and cognitive function in similar manner to SNRIs (selective noradrenaline/serotonine reuptake inhibitor) [47].

Moreover; Jardel et al. study pointed that because of ginkgo is a reversible monoamine oxidase inhibitor like moclobemide which is approximately free from tranquilizer consequences and studies done normal persons have proposed with the intention of moclobemide be impartial with observe to cognitive capacity but moclobemide do not affect cognitive ability in any way and improve the cognition further than monoamine oxidase a inhibition were considered [48]

Even though the precise scenery of the central cognitive potentiating effect as suggested by Ansel et al. study which showed that piracetam leading to dramatic changes in neuronal electrical action throughout modulation of acetyl cholinesterase as measured by electroencephalograph so augment the effects of ginkgo biloba [49].

Piractam affect the ginkgo biloba on cognitive and working memory functions while ginkgo biloba enhance effects of piracetam on psychomotor performance therefore; piracetam or ginkgo biloba modulate each other in advancing the working memory, cognitive function and psychomotor performance in normal healthy volunteers.

\section{Conclusions}

Combined effects of piracetam and ginkgo biloba produced more significant effects than either ginkgo biloba or piracetam alone on cognitive function and working memory with regarding to the psychomotor performances in healthy young subjects.

\section{References}

1. Singh B, Kaur P, Gopichand, Singh RD, Ahuja PS (2008) Biology and chemistry of Ginkgo biloba. See comment in PubMed Commons below Fitoterapia 79: 401-418.

2. Jingjing C, Tao Z, Bo J, Whamming M (2012). Characterization and antioxidant activity of ginkgo bilobaexocarp polysaccharides carbohydrate polymers 4: 40-45.

3. Jang $\mathrm{CH}$, Cho YB, Choi $\mathrm{CH}$ (2012) Effect of ginkgo biloba extract on recovery after facial nerve crush injury in the rat. See comment in PubMed Commons below Int J PediatrOtorhinolaryngol 76: 1823-1826.

4. Anne E (2012) Mitochondrial effects of ginkgo biloba extract. International psycho geriatrics. 4: s18-s20.

5. Qiu F, Friesen JB, McAlpine JB, Pauli GF (2012) Design of countercurrent separation of Ginkgo bilobaterpene lactones by nuclear magnetic resonance. See comment in PubMed Commons below J Chromatogr A 1242: 26-34.

6. Xiang Z, Wu-fang Z, Dong-feng Z, Chen da C, Xiu MH, et al. (2012) Brain-derived neurotrophic factor levels and its val66met gene polymorphism predict tardive dyskinesia treatment response to ginkgo biloba.biological psychiatry 72: 700-706

7. Jia-shiong C, Yung-hsiang C, Po-hsun H, Tsai HY, Chen YL, et al. (2012). Ginkgo biloba extract reduces high-glucose-induced endothelial adhesion by inhibiting the redox-dependent interleukin-6 pathways.cardiovasculardiabetology11:49-56.

8. Abdel-Wahab BA, Abd El-Aziz SM (2012) Ginkgo biloba protects against intermittent hypoxia-induced memory deficits and hippocampal DNA damage in rats. See comment in PubMed Commons below Phytomedicine 19: 444-450.
9. Nada SE, Shah ZA (2012) Preconditioning with Ginkgo biloba (EGb $761^{\oplus}$ ) provides neuroprotection through HO1 and CRMP2. See comment in PubMed Commons below Neurobiol Dis 46: 180-189.

10. Deepak A. Gowda N (2007).Piracetam in post concussion syndrome: preliminary results of a randomized study using SPECT. The Indian Journal of Neurotrauma 4:109-114

11. He Z, Liao Y, Zheng M, Zeng FD, Guo LJ (2008) Piracetam improves cognitive deficits caused by chronic cerebral hypoperfusion in rats. See comment in PubMed Commons below Cell MolNeurobiol 28: 613-627.

12. Kertu R, Laura O, Sulev K, Toshimitsu M et al. (2012). Rimonabant attenuates amphetamine sensitisation in a CCK2 receptor-ependent manner. Behavioural Brain Research 1:335-339.

13. Osvaldo G, Giovanna P, Maria C (2005) Behavioral effects of acute and repeated cocaine treatments: a comparative study in sensitization-prone RHA rats and their sensitization-resistant RLA counterparts. Psychopharmacology 180:530-538.

14. Candice M, Richard D, Morey M (2013). Asymmetric cross-domain interference between two working memory tasks: Implications for models of working memory. Journal69:324-348

15. Barreiro KA, Suárez LD, Lynch VM, Molina VA, Delorenzi A (2013) Memory expression is independent of memory labilization/ reconsolidation. See comment in PubMed Commons below Neurobiol Learn Mem 106: 283-291.

16. Jennifer R, Thomas P, Isabel G (2013). How does using object names influence visual recognition memory? Journal of Memory and Language 68: 10-25.

17. Luo YX, Xue YX, Shen HW, Lu L (2013) Role of amygdala in drug memory. See comment in PubMed Commons below Neurobiol Learn Mem 105: 159-173.

18. Thullier F, Lepelley MC, Lestienne FG (2008) An evaluation tool for psychomotor performance during visual motor task: an application of information theory. See comment in PubMed Commons below J Neurosci Methods 171: 183-189.

19. Jozarni D, Lange Kuipers G, Duisterwinkel M, Fervor H (2008). Does the critical flicker fusion threshold distinguish patients with schizophrenia from healthy controls?schizophrenia research 102:106-107.

20. Chen YN, Mitra S, Schlaghecken F (2008) Sub-processes of working memory in the N-back task: an investigation using ERPs. See comment in PubMed Commons below ClinNeurophysiol 119: 1546-1559.

21. Stahlhut L, Grotemeyer KH2, Husstedt IW1, Evers S3 (2014) The impact of stroke on cognitive processing - a prospective event-related potential study. See comment in PubMed Commons below J NeurolSci 339: 157-163.

22. Guandalini L, Martini E, Di Cesar L, Dei S, Manetti D(2012). Influence of ring size on the cognition-enhancing activity of DM235 and MN19, two potent nootropic drugs. Bioorganic \& Medicinal Chemistry Letters 22: 1936-1939.

23. Noemi R, Jesus F, Carmen M (2008). Effects of chronic administration of SGS-111 during adulthood and during the pre- and post-natal periods on the cognitive deficits of Ts65Dn mice, a model of Down syndrome. Behavioral Brain Research 188: 355-367.

24. Szalma I, Kiss A, Kardos L, Horváth G, Nyitrai E, et al. (2006) Piracetam prevents cognitive decline in coronary artery bypass: a randomized trial versus placebo. See comment in PubMed Commons below Ann ThoracSurg 82: 1430-1435.

25. Evans JG, Wilcock G, Birks J (2004) Evidence-based pharmacotherapy of Alzheimer's disease. See comment in PubMed Commons below Int J Neuropsychopharmacol 7: 351-369.

26. Chatterjie N, Alexander G, Wang H (2001) Synthesis of valproic acid amides of a melatonin derivative, a piracetam and amantadine for biological tests. See comment in PubMed Commons below Neurochem Res 26: 1171-1176.

27. Güngör L, Terzi M, Onar MK (2011) Does long term use of piracetam improve speech disturbances due to ischemic cerebrovascular diseases? See comment in PubMed Commons below Brain Lang 117: 23-27. 
Citation: Alkuraishy H, Algareeb A, Albuhadilly A, Almgoter B (2014) Modulation Effects of Piracetam and Ginkgo Biloba on the Cognitive and Working Memory Functions: Psychometric Study. J Neurol Neurophysiol 5: 234. doi:10.4172/2155-9562.1000234

Page 6 of 6

28. Chen A., Muoi T. Yan P (2014). Measurement and correlation for the solubilities of cinnarizine, pentoxifylline, and piracetam in supercritical carbon dioxide.Fluid Phase Equilibria 367: 15:182-187.

29. Aliya A, kalavathy R, Siti M (2014). Total isoflavones from soybean and temped reversed scopolamine-induced amnesia, improved cholinergic activities and reduced neuron inflammation in brain. Food and chemical toxicology65: 120-128.

30. Kehr J, Yoshitake S, Ijiri S, Koch E, Noldner T(2012). Ginkgo biloba leaf extract and its specific acylatedflavonol constituents increase dopamine and acetylcholine levels in the rat medial prefrontal cortex: possible implications for the cognitive enhancing properties of egb 761 . International psycho geriatrics 24: s25-s34.

31. Yang JF, Zhou DY, Liang ZY (2009) A new polysaccharide from leaf of Ginkgo biloba L. See comment in PubMed Commons below Fitoterapia 80: 43-47.

32. Ding S, Dudley E, Plummer S, Tang J, Newton RP, et al. (2008) Fingerprint profile of Ginkgo biloba nutritional supplements by LC/ESI MS/MS. See comment in PubMed Commons below Phytochemistry 69: 1555-1564.

33. Kotil K, Turgay B, Tugrul T, Ton T, Kucukhuseyin C, et al. (2008) Investigation of the dose-dependent antivasospasmic effect of ginkgo biloba extract in experimental subarachnoid hemorrhage.journal of clinical neuroscience 15:1382-1386.

34. Mahadevan S, Park Y (2008) Multifaceted therapeutic benefits of Ginkgo biloba L.: chemistry, efficacy, safety, and uses. See comment in PubMed Commons below J Food Sci 73: R14-19.

35. Liuping F, Shaodong D, Yuanfa L, Lianzhong A (2012). Dehydration of crude protein from ginkgo biloba 1. By microwave freeze drying.international journal of biological macromolecules 50: 1008-1010.

36. Kennedy DO, Scholey AB, Wesnes KA (2000) The dose-dependent cognitive effects of acute administration of Ginkgo biloba to healthy young volunteers. See comment in PubMed Commons below Psychopharmacology (Berl) 151: 416-423.

37. Droy-Lefaix MT (1997) Effect of the antioxidant action of Ginkgo biloba extract (EGb 761) on aging and oxidative stress. See comment in PubMed Commons below Age (Omaha) 20: 141-149.

38. Ryu KH, Han HY, Lee SY, Jeon SD, Im GJ, et al. (2009) Ginkgo biloba extract enhances antiplatelet and antithrombotic effects of cilostazol without prolongation of bleeding time. See comment in PubMed Commons below Thromb Res 124: 328-334.

39. Cohen-Salmon C, Venault P, Martin B, Raffalli-Sébille MJ, Barkats M, et al. (1997) Effects of Ginkgo biloba extract (EGb 761) on learning and possible actions on aging. See comment in PubMed Commons below J Physiol Paris 91: 291-300.

40. Persson J, Bringlöv E, Nilsson LG, Nyberg L (2004) The memoryenhancing effects of Ginseng and Ginkgo biloba in healthy volunteers. See comment in PubMed Commons below Psychopharmacology (Berl) 172: 430-434.

41. Ming-xing Z, Zhen-hua D, Zhong-hai Y, Shi-yuan X (2012). Effects of ginkgo biloba extract in improving episodic memory of patients with mild cognitive impairment: a randomized controlled trial .Journal of chinese integrative 10:345-365.

42. Zhang SJ, Xue ZY (2012) Effect of Western medicine therapy assisted by Ginkgo biloba tablet on vascular cognitive impairment of none dementia. See comment in PubMed Commons below Asian Pac J Trop Med 5: 661-664.

43. Ixchel Herrera G, Estevez G, Jorge H, Daniel H, Montelongo-Pedraza P, et al. (2010). Major depressive disorder in recovery and neuropsychological functioning: effects of selective serotonin reuptake inhibitor and dual inhibitor depression treatments on residual cognitive deficits in patients with major depressive disorder in recovery. journal of affective disorders 123:341-350.

44. García-Cabeza I, de Blas MM, Epifanio MM, de Chávez MG (2011) Cognitive deterioration after venlafaxine overdose. See comment in PubMed Commons below J Emerg Med 40: e103-106.

45. de Jongh R, Bolt I, Schermer M, Olivier B (2008) Botox for the brain: enhancement of cognition, mood and pro-social behavior and blunting of unwanted memories. See comment in PubMed Commons below NeurosciBiobehav Rev 32: 760-776.

46. Deepak P, Kumar N (2011). Duloxetine- pharmacological aspects. Int $j$ biol med res 2: 589-592.

47. MahableshwarkarR, Jacobsen P, Chen I, Simon S (2014). A randomized, double-blind, placebo-controlled, duloxetine-referenced study of the efficacy and tolerability of vortioxetine in the acute treatment of adults with generalised anxiety disorder.Int J ClinPract 68: 49-59.

48. Jardel G, Villarinho B, Kelly de V, Pinheirfrancielle D, Oliveira SM, Machado P, et al.(2013) The antinociceptive effect of reversible monoamine oxidase-a inhibitors in a mouse neuropathic pain model.Progress in neuro-psychopharmacology and biological. Psychiatry 44:136-142.

49. Ansel H, Dustin W, Mohammed F, Andrew T (2013). Pet imaging of acetylcholinesterase Inhibitor-induced effects on a4 $\hat{\mathrm{I}}^{2} 2$ nicotinic Acetylcholine receptor binding synapse 67:882-886. 